\title{
CAD-CAE Integration of Horizontal Axis Wind Turbine
}

\author{
Armaghan Ahmad, Zohaib Elahi, Muhammad Babar* \\ Institute of Industrial and Manufacturing Engineering, Pakistan Navy Engineering College, \\ National University of Science and Technology, Karachi - Pakistan. \\ *Corresponding Author: engr.mbabar@gmail.com
}

Copyright (C) 2013 Horizon Research Publishing all rights reserved.

\begin{abstract}
About 1\% to 2\% of the energy coming from the sun is converted into wind energy. The technology of extracting energy from the wind has evolved dramatically over the last few decades because of the fact that the energy crises that we are facing worldwide. This paper presents design of $5 \mathrm{~kW}$ Horizontal Axis Wind Turbine using CAD and CAE software for modeling and analysis in order to get rid of conventional methods of analysis, which will be productive for the industry.In this paper, theoretical calculations for the design of $5 \mathrm{~kW}$ horizontal axis wind turbine is also presented. It also discusses the modeling of blade and its analysis using high-tech software. Lastly it concludes with the comparison of theoretical and computer based design and analysis.
\end{abstract}

Keywords CAD, CAE, Horizontal Axis Wind Turbine

\section{Introduction}

Wind energy appears as a result of solar energy. About $1 \%$ to $2 \%$ of the energy coming from the sun is converted into wind energy. Wind Turbines harness the kinetic energy of the wind and convert it into electrical energy. This is accomplished by turning blades called airfoils, which drive a shaft, which turns a motor (turbine), which is connected to a generator. Wind turbines need to be much higher than windmills (80-200 feet tall) and usually have 2-3 blades. Wind turbines can be used to provide electricity to homes (especially in rural areas), buildings and even a society. The electricity produced can be stored in batteries for use when wind speeds are too low to produce electricity or when high winds could damage the turbine (in this case, the wind turbine can be turned off to prevent the generator from overheating). [1-4].

Wind turbine power production depends on the interaction between the rotor and the wind. Experience has shown that the major aspects of wind turbine performance (mean power output and mean loads) are determined by the aerodynamic forces generated by the mean wind. These can only be understood once the aerodynamics of steady state operation has been understood [2, 3-7].
Practical horizontal axis wind turbine designs use airfoils to transform the kinetic energy in the wind into useful energy. A number of authors have derived methods for predicting the steady state performance of wind turbine rotors. The classical analysis of the wind turbine was originally developed by Betz and Glauert (Glauert, 1935) in the 1930's. The sudden increase in the price of oil stimulated a number of substantial Government-funded programs of research, development and demonstration. In the USA this led to the construction of a series of prototype turbines starting with the $38 \mathrm{~m}$ diameter $100 \mathrm{~kW}$ Mod- 0 in 1975 and culminating in the $97.5 \mathrm{~m}$ diameter 2.5 MW Mod-5B in 1987. Similar programs were pursued in the UK, Germany and Sweden. There was considerable uncertainty as to which architecture might prove most cost-effective and several innovative concepts were investigated at full scale. In Canada, a $4 \mathrm{MW}$ vertical-axis Darrieus wind turbine was constructed and this concept was also investigated in the $34 \mathrm{~m}$ diameter Sandia Vertical Axis Test Facility in the USA. In the UK, an alternative vertical-axis design using straight blades to give an ' $\mathrm{H}$ ' type rotor was proposed by Dr Peter Musgrove and a $500 \mathrm{~kW}$ prototype constructed. In 1981 an innovative horizontal-axis $3 \mathrm{MW}$ wind turbine was built and tested in the USA. This used hydraulic transmission and, as an alternative to a yaw drive, the entire structure was orientated into the wind. The best choice for the number of blades remained unclear for some while and large turbines were constructed with one, two or three blades [1-4].

Much important scientific and engineering information was gained from these Government-funded research programs and the prototypes generally worked as designed. However, it has to be recognized that the problems of operating very large wind turbines, unmanned and in difficult wind climates were often under estimated and the reliability of the prototypes was not good. At the same time as the multi-megawatt prototypes were being constructed private companies, often with considerable state support, were constructing much smaller, often simpler, turbines for commercial sale. In particular the financial support mechanisms in California in the mid-1980s resulted in the installation of a very large number of quite small $(100 \mathrm{~kW})$ wind turbines. A number of these designs also suffered from various problems but, being smaller, they were in general easier to repair and modify. The so-called 'Danish' wind 
turbine concept emerged of a three-bladed, stall-regulated rotor and a fixed-speed, induction machine drive train. This deceptively simple architecture has proved to be remarkably successful and has now been implemented on turbines as large as $60 \mathrm{~m}$ in diameter and at ratings of 1.5 MW [3-7].

Subsequently, the theory was expanded and thus, momentum theory and blade element theory are combined into a strip theory that enables calculation of the performance characteristics of an annular section of the rotor. The characteristics for the entire rotor are then obtained by integrating, or summing, the values obtained for each of the annular sections. However the conservative methods require enormous amount of time and capital for its design and analysis [8-11].

Therefore, in this paper the major emphasis is on design of $5 \mathrm{~kW}$ Horizontal Axis Wind Turbine using CAD and CAE software for modeling and analysis in order to get rid of conventional methods of analysis, which will be productive for the industry. This research uses Pro/ENGINEER, GAMBIT and FLUENT software tools for part modeling and analysis. Paper also discusses the modeling of blade and its analysis using high-tech software and concludes with the comparison of theoretical and computer based design and analysis.

\section{Theoretical Design of 5kw Hawt Rotor}

\subsection{Basic Rotor Parameters}

As we intended to design the horizontal axis wind turbine of $5 \mathrm{~kW}$ at rated wind speed of $13 \mathrm{~m} / \mathrm{s}$. Therefore, $\mathrm{P}=5000$ Watts and $U=13 \mathrm{~m} / \mathrm{s}$. Since, Most efficient modern wind turbines have power coefficient of 0.4 or less, so considering Power co-efficient $C_{p}=0.35$. Moreover, it is also found that
Optimum tip speed ratio for modern wind turbines is usually more than 5 , so considering tip speed ratio $\lambda=7$.

The number of blades of wind turbine largely dictated by the tip speed ratio, therefore this paper is designing for 3 bladed rotors.

Blade length $\mathrm{R}$ can be estimated by simplifying Equation 3.8 as follows:

$$
\mathrm{P}=\frac{1}{2} \rho \mathrm{U}^{3} \pi \mathrm{R}^{2}\left(\eta_{\text {mech }} \mathrm{C}_{\mathrm{p}}\right)
$$

Where, $\rho=$ density of air $=1.225 \mathrm{~kg} / \mathrm{m}^{3}$ and assuming, $\eta_{\text {mech }}=85 \%$, the blade length which comes out to be 2.15 meters.

But, keeping in view various aerodynamic losses, $\mathrm{R}=3$ meters is considered. Thus, Angular speed $\Omega$ of the rotor can be calculated as

$$
\Omega=\frac{\lambda U}{R}=30.33 \mathrm{rad} / \mathrm{sec}
$$

By equating values in Equation 4.2 we get:

$\Omega=30.33 \mathrm{rad} / \mathrm{sec}$ or $289.66 \mathrm{rpm}$

In this paper, NACA 4415 is selected as airfoil due to its better lift to drag ratio, good stall characteristics and cheap manufacturing.

For design of blade shape we require maximum lift to drag ratio $\left(\mathrm{C}_{\mathrm{l}} / \mathrm{C}_{\mathrm{d}}\right)$ at subsequent angle of attack $\alpha$ and Reynolds number. It is fact that for given parameters maximum $C_{l} / C_{d}$ occurs at an angle of attack of 5.5 . Thus, $\alpha=5.5^{\circ}, \mathrm{C}_{l}=$ 0.975 and $C_{d}=0.00775$ is considered for simulation purposes.

\subsection{Blade Shape}

According to Blade Element Theory we will divide the blade into $\mathrm{N}=12$ equal parts. Thus, the parameters at each division/section of blade are shown in Table 1.

\begin{tabular}{|c|c|c|c|c|c|c|c|c|}
\hline \multirow[b]{2}{*}{$\boldsymbol{r}(\mathrm{m})$} & \multicolumn{3}{|c|}{ Prandtl's Correction Factor } & \multicolumn{3}{|c|}{ Interference Factors } & \multirow{2}{*}{$\begin{array}{c}\text { Velocity } \\
\boldsymbol{U}_{\boldsymbol{r e l}} \\
(\mathrm{m} / \mathrm{s})\end{array}$} & \multirow{2}{*}{$\begin{array}{c}\begin{array}{c}\text { Reynolds } \\
\text { Number }\end{array} \\
\boldsymbol{R} \boldsymbol{e}\end{array}$} \\
\hline & $F_{t i p}$ & $F_{\text {root }}$ & $\boldsymbol{F}$ & $\begin{array}{c}\text { Local } \\
\text { Solidity }(\sigma)\end{array}$ & $\begin{array}{c}\text { Axial } \\
(\boldsymbol{a})\end{array}$ & $\begin{array}{c}\text { Rotational } \\
\left(\boldsymbol{a}^{\prime}\right)\end{array}$ & & \\
\hline 0.3 & 1.000 & 0.569 & 0.569 & 0.081 & 0.061 & 0.047 & 19.596 & $6.69 \mathrm{E}+05$ \\
\hline 0.5 & 1.000 & 0.976 & 0.976 & 0.449 & 0.325 & 0.144 & 19.491 & $6.28 \mathrm{E}+05$ \\
\hline 0.75 & 1.000 & 1.000 & 1.000 & 0.243 & 0.326 & 0.067 & 25.811 & $6.75 \mathrm{E}+05$ \\
\hline 1 & 1.000 & 1.000 & 1.000 & 0.149 & 0.329 & 0.039 & 32.702 & $6.97 \mathrm{E}+05$ \\
\hline 1.25 & 1.000 & 1.000 & 1.000 & 0.099 & 0.331 & 0.025 & 39.841 & $7.07 \mathrm{E}+05$ \\
\hline 1.5 & 1.000 & 1.000 & 1.000 & 0.070 & 0.331 & 0.018 & 47.119 & $7.14 \mathrm{E}+05$ \\
\hline 1.75 & 0.999 & 1.000 & 0.999 & 0.052 & 0.332 & 0.013 & 54.484 & $7.17 \mathrm{E}+05$ \\
\hline 2 & 0.997 & 1.000 & 0.997 & 0.041 & 0.333 & 0.010 & 61.921 & $7.20 \mathrm{E}+05$ \\
\hline 2.25 & 0.988 & 1.000 & 0.988 & 0.032 & 0.335 & 0.008 & 69.476 & $7.23 \mathrm{E}+05$ \\
\hline 2.5 & 0.955 & 1.000 & 0.955 & 0.026 & 0.343 & 0.007 & 77.404 & $7.28 \mathrm{E}+05$ \\
\hline 2.75 & 0.829 & 1.000 & 0.829 & 0.022 & 0.376 & 0.006 & 87.016 & $7.47 \mathrm{E}+05$ \\
\hline 2.95 & 0.446 & 1.000 & 0.446 & 0.018 & 0.528 & 0.010 & 105.203 & $8.30 \mathrm{E}+05$ \\
\hline
\end{tabular}

Table 1. Parameters At Each Division/Section Of Blade

Note: At the root and at the tip if we take exact values of $r$, the correction factor become zero. There to find an appropriate value of $\mathrm{F}$ we deviate slightly from the exact values and take $r_{\text {root }}=0.3 \mathrm{~m}$ and $r_{\text {tip }}=2.95 \mathrm{~m}$. 


\subsection{Calculation of Performance Parameters}

For estimating wind turbine rotor performance various factors are need to be calculated as shown in Table 2 .

Table 2. Section chord width and pitch angle at each division of blade

\begin{tabular}{|c|c|c|c|c|c|}
\hline $\boldsymbol{r}(\mathrm{m})$ & $\lambda_{\boldsymbol{r}}$ & $\boldsymbol{\varphi}(\mathrm{deg})$ & $\boldsymbol{c}(\mathrm{m})$ & $\boldsymbol{\theta}_{\boldsymbol{p}}(\mathrm{deg})$ & $\boldsymbol{t}_{\boldsymbol{m a x}}$ \\
\hline 0.250 & 0.583 & 39.829 & 0.498 & 34.329 & 0.250 \\
\hline 0.500 & 1.167 & 27.068 & 0.471 & 21.568 & 0.500 \\
\hline 0.750 & 1.750 & 19.830 & 0.382 & 14.330 & 0.750 \\
\hline 1.000 & 2.333 & 15.466 & 0.311 & 9.966 & 1.000 \\
\hline 1.250 & 2.917 & 12.616 & 0.259 & 7.116 & 1.250 \\
\hline 1.500 & 3.500 & 10.630 & 0.221 & 5.130 & 1.500 \\
\hline 1.750 & 4.083 & 9.174 & 0.192 & 3.674 & 1.750 \\
\hline 2.000 & 4.667 & 8.063 & 0.170 & 2.563 & 2.000 \\
\hline 2.250 & 5.250 & 7.190 & 0.152 & 1.690 & 2.250 \\
\hline 2.500 & 5.833 & 6.485 & 0.137 & 0.985 & 2.500 \\
\hline 2.750 & 6.417 & 5.905 & 0.125 & 0.405 & 2.750 \\
\hline 3.000 & 7.000 & 5.420 & 0.115 & -0.080 & 3.000 \\
\hline
\end{tabular}

\subsection{Thrust on the Rotor}

Thrust on the rotor is a force on the blade acts due to force normal to the plane of rotation and can be calculated as follows:

$$
\mathrm{F}_{\mathrm{N}}=\frac{1}{2} \rho B \mathrm{U}^{2} \int_{\text {root }}^{\mathrm{tip}} \mathrm{X} \mathrm{dr}=611.49 \mathrm{~N}
$$

However, Tangential force on the blade can be calculated as follows:

$$
\mathrm{F}_{\mathrm{T}}=\frac{1}{2} \rho \mathrm{BU}^{2} \int_{\text {root }}^{\mathrm{tip}} \mathrm{Ydr}=133.41 \mathrm{~N}
$$

On the other hand, Torque produces the useful rotation and it comes into action in the presence of tangential force. It can be calculated as follows:

$$
\mathrm{Q}=\frac{1}{2} \rho \mathrm{BU}^{2} \int_{\text {root }}^{\mathrm{tip}} \mathrm{Zdr}=161.21 \mathrm{~N} . \mathrm{m}
$$

\subsection{Selection of Blade Material}

In this paper, material of wind turbine blade is fiberglass reinforced plastic GRP. Its physical and mechanical properties are given below:

Table 3. Properties of Material

\begin{tabular}{|cc|}
\hline Density & $1800 \mathrm{~kg} / \mathrm{m} 3$ \\
Modulus of Elasticity & $20700 \mathrm{MPa}$ \\
Tensile Strength at break & $85 \mathrm{MPa}$ \\
Compressive Strength at yield or break & $200 \mathrm{MPa}$ \\
Poisson's Ratio & 0.3 \\
Weight of Blade & $447 \mathrm{~N}$ \\
\hline
\end{tabular}

\subsection{Bending of Blade Due to Weight and Tangential Force}

For making analysis easier we assume the blade to be rectangular. Now weight of the blade would act through center of gravity and tangential force, we consider, is acting at tip of blade as shown below for designing at extreme conditions.

From Figure 1, Moment $=M=W_{b} \times 1.35+F_{T} \times$ $2.7=723.48 \mathrm{~N} . \mathrm{m}$

$$
\begin{gathered}
\text { Moment of Inertia }=I=\frac{t_{a v g} c_{a v g}{ }^{3}}{12}=0.00004883 \mathrm{~m}^{4} \\
y=c_{a v g} / 2=0.125 \mathrm{~m} \\
\text { Bending Stress }=\sigma_{b}=\frac{M y}{I}=1.852 \mathrm{MPa}
\end{gathered}
$$

From Maximum Normal Stress Theory we have,

$$
\begin{aligned}
\text { Factor of Safety } & =\frac{\text { Ultimate tensile stress }}{\text { Bending stress produced }}=\frac{85}{1.852} \\
& =46
\end{aligned}
$$

Hence, the design is safe under bending due to weight and tangential force.

\subsection{Bending of Blade Due to Thrust Force}

Here again we consider the blade to be rectangular and thrust force is acting at tip of blade as shown below for designing at extreme conditions.

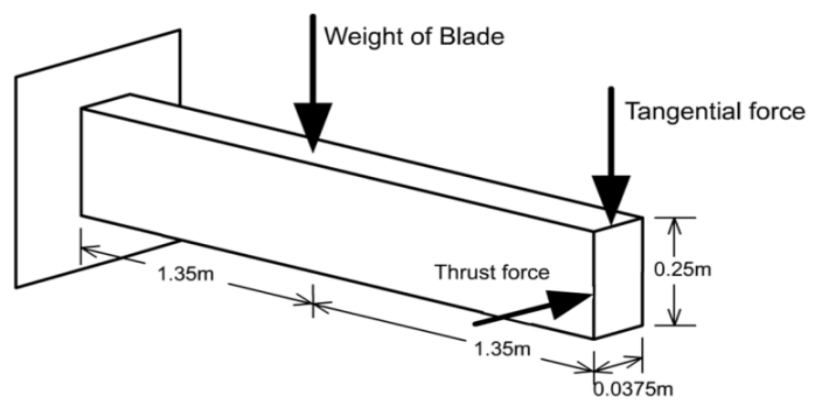

Figure 1. Bending Of Blade due to Weight and Tangential Force

From Figure 1,

$$
\text { Moment }=\mathrm{M}=\mathrm{F}_{\mathrm{N}} \times 2.7=550.34 \mathrm{~N} . \mathrm{m}
$$

Moment of Inertia $=I=\frac{c_{a v g} t_{a v g}{ }^{3}}{12}=0.000001099 \mathrm{~m}^{4}$

$$
\mathrm{y}=\mathrm{t}_{\mathrm{avg}} / 2=0.01875 \mathrm{~m}
$$

Bending Stress $=\sigma_{\mathrm{b}}=\frac{\mathrm{My}}{\mathrm{I}}=9.392 \mathrm{MPa}$

From Maximum Normal Stress Theory we have,

Factor of Safety $=\frac{\text { Ultimate tensile stress }}{\text { Bending stress produced }}=\frac{85}{9.392}=9$

Hence, the design is safe under bending due to thrust force. 


\subsection{Bending of Blade Due to Thrust Force}

Here again we consider the blade to be rectangular and thrust force is acting at tip of blade as shown below for designing at extreme conditions.

From Figure 1,

$$
\text { Moment }=\mathrm{M}=\mathrm{F}_{\mathrm{N}} \times 2.7=550.34 \mathrm{~N} . \mathrm{m}
$$

Moment of Inertia $=I=\frac{c_{\text {avg }} t_{\text {avg }}{ }^{3}}{12}=0.000001099 \mathrm{~m}^{4}$

$\mathrm{y}=\mathrm{t}_{\mathrm{avg}} / 2=0.01875 \mathrm{~m}$

Bending Stress $=\sigma_{\mathrm{b}}=\frac{\mathrm{My}}{\mathrm{I}}=9.392 \mathrm{MPa}$

From Maximum Normal Stress Theory we have,

Factor of Safety $=\frac{\text { Ultimate tensile stress }}{\text { Bending stress produced }}=\frac{85}{9.392}=9$

Hence, the design is safe under bending due to thrust force.

\subsection{Stress on Blade Due to Centrifugal Force}

Centrifugal force on blade causes direct tensile stress on the blade. If we assume the blade to be rectangular having centre of gravity $r_{c g}$ at geometric centre then centrifugal force estimated to be:

$$
\mathrm{F}_{\mathrm{c}}=\frac{\mathrm{W}_{\mathrm{b}}}{\mathrm{g}} \mathrm{r}_{\mathrm{cg}} \Omega^{2}=56.595 \mathrm{kN}
$$

Since we have considered the blade as rectangular so area subjected to the stress would be:

$$
\mathrm{A}_{\mathrm{c}}=\mathrm{t}_{\mathrm{avg}} \times \mathrm{c}_{\mathrm{avg}}=0.009375 \mathrm{~m}^{2}
$$

Stress due to centrifugal force would be:

$$
\sigma_{\mathrm{c}}=\mathrm{F}_{\mathrm{c}} / \mathrm{A}_{\mathrm{c}}=6.037 \mathrm{MPa}
$$

From Maximum Normal Stress Theory we have,

$$
\text { Factor of Safety }=\frac{\text { Ultimate tensile stress }}{\text { Working Stress }}=\frac{85}{6.037}=14
$$

Hence, the design is safe under tension due to centrifugal force.

\subsection{Calculation of Angle of Attack}

The selection of airfoil section for wind turbine blade is one of the major issues for achieving higher lift to drag ratio at particular angle of attack. For this purpose we have analyzed NACA 4415 airfoil section using FLUENT at various angles of attacks for achieving higher lift to drag ratios by considering following conditions:

$$
\rho=\text { density of air }=1.225 \mathrm{~kg} / \mathrm{m}^{3}
$$

$$
\begin{gathered}
\mu=\text { viscosity of air }=1.7894 \times 10^{-5} \mathrm{~kg} / \mathrm{m} . \mathrm{s} \\
\mathrm{v}=\text { velocity of air }=105 \mathrm{~m} / \mathrm{s}
\end{gathered}
$$

From results it is clear that maximum lift to drag ratio can be achieved at an angle of attack of $5.5^{\circ}$ which is similar to the general. The pressure and velocity distribution in the vicinity of the airfoil at an angle of attack of $5.5^{\circ}$ is shown in Figure 2, 3 and 4.

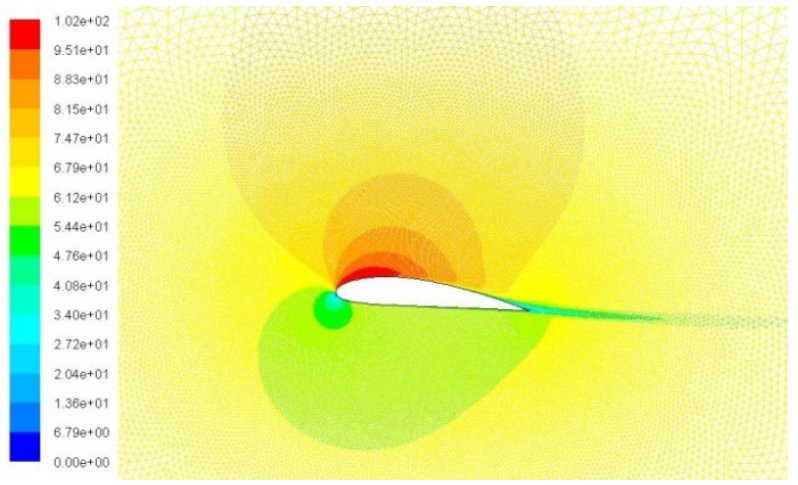

Figure 2. Velocity Contours $(\mathrm{m} / \mathrm{s})$

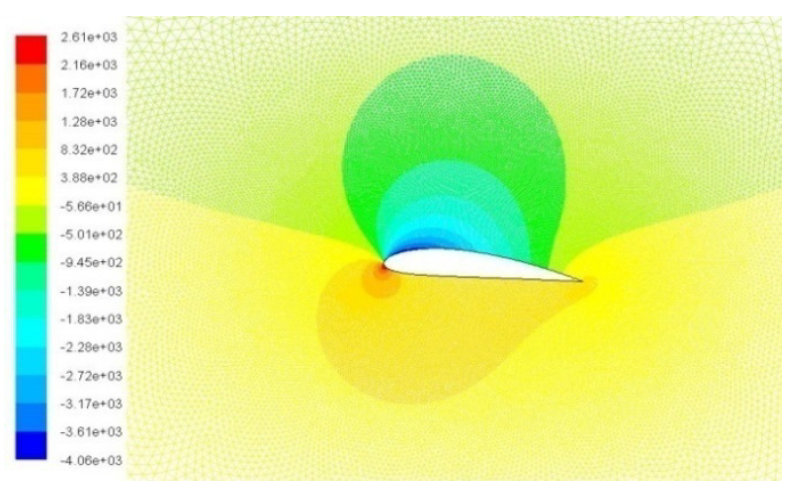

Figure 3. Pressure contours (Pascal)

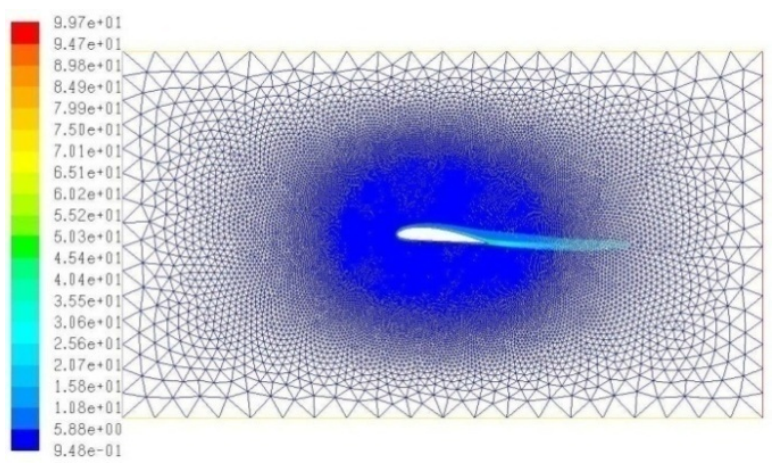

Figure 4. Contour of Turbulent Kinetic Energy (m2/s2)

Table 4. Lift to Drag Ratio for NACA 4415 Airfoil

\begin{tabular}{|ccccccccc|}
\hline $\begin{array}{c}\text { Angle of Attack } \\
\text { (deg) }\end{array}$ & 1 & 2 & 3 & 4 & 5 & 5.5 & 6 & 7 \\
\hline Lift to Drag ratios & 42.836 & 49.613 & 53.874 & 58.824 & 59.564 & 62.725 & 59.738 & 60.812 \\
\hline
\end{tabular}




\section{Solid Modeling (Wind Turbine Rotor)}

Stress analysis that we have performed previously, in chapter 4, was based on theoretical calculations. For stress analysis using Pro/ENGINEER, it is requires to build solid model for each component of wind turbine rotor. Fig 5. shows the Solid model of complete Assembly of blades, bolts, hub and shaft:

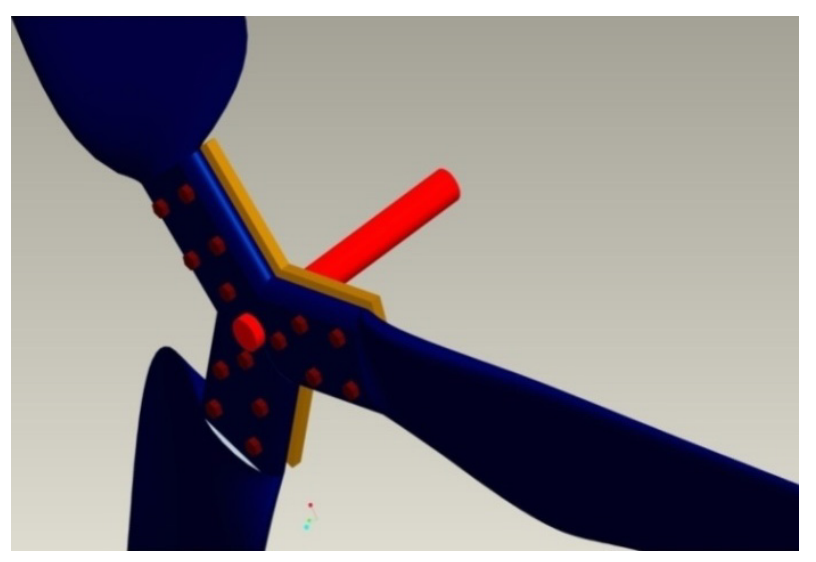

Figure 5. Assembly of Wind Turbine Rotor

\section{Analysis}

\subsection{Bending of Blade due to Weight and Tangential Force}

Bending due to weight and tangential forces calculated theoretically in chapter 4 is now analyzed through Pro/MECHANICA as shown below:

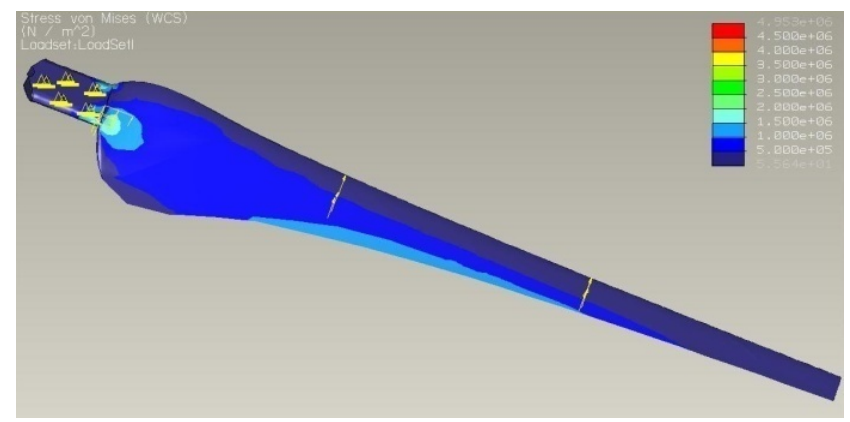

Figure 6. Bending of Blade due to Weight and Tangential Force

Above figure illustrate that the design is safe under bending due to weight and tangential force and can be compared with the theoretical analysis previously discussed in section III.

\subsection{Bending of Blade due to Thrust Force}

In the similar way the bending of blade due to thrust force is also analyzed through Pro/MECHANICA and the obtained results are as under.

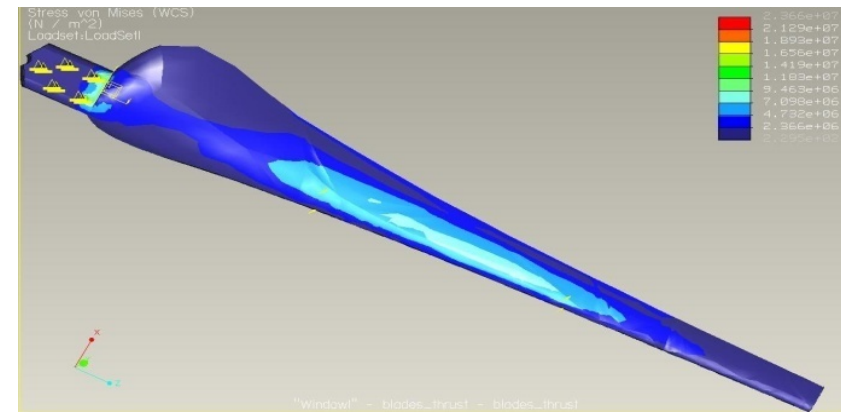

Figure 7. Bending of Blade due to Thrust Force

It is clear from above results that our design is safe and bending due to thrust force is prevailing under design limits.

\subsection{Stress on Blade due to Centrifugal Force}

Using same Pro/MECHANICA bending of blade due to centrifugal force results obtained is as under.

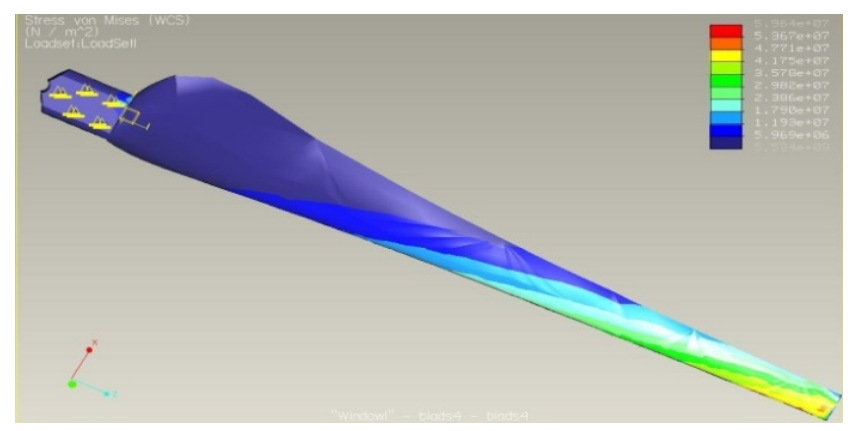

Figure 8. Stresses on Blade due to Centrifugal Force

After analysis we can conclude that the stress on blade due centrifugal force is under design limits.

\subsection{Stresses on Blade Due to Combine Effect of all Forces}

A stress on blade due to combine effect of all forces which cannot be analyzed theoretically is examined inPro/MECHANICA. Its results are as under:

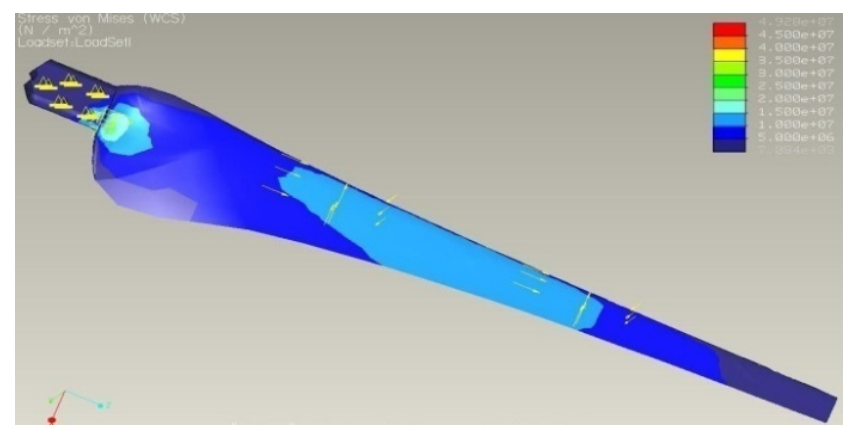

Figure 9. Stresses on Blade due to combine effect of all

\section{Conclusion}

Pakistan has a considerable potential of wind energy in the 
coastal belt of Sindh, Baluchistan and as well as in the desert areas of Punjab and Sindh. This renewable source of energy has however, not so far been utilized significantly.This paper shows the advantages of utilizing CAD and CAE in wind turbine blade design. This paper also proven it's accuracy over manufacturing risk by comparing theoretic with $\mathrm{CAD} / \mathrm{CAE}$ analyzed wind turbine. The benefits of the proposed method are to reduce process time, manufacturing steps, production cost and erratum due to the trial and error process. Furthermore, the performance of wind blade manufacturing, wind turbine industrials and associated industrials in Pakistan cold enhance to compete in the continuously growing and change in nationwide as well as in global market.

\section{REFERENCES}

[1] Manwell, James F., Jon G. McGowan, and Anthony L. Rogers. "Wind energy explained: theory, design and application. 2002." John Wiley \& Sons Ltd, UK(2002): 577.

[2] Burton, T., Jenkins, N., Sharpe, D., \&Bossanyi, E. (2011). Wind energy handbook. Wiley.
[3] Hau, Erich, and Heidelberger Platz. "Wind Turbines-Fundamentals, Technologies, Application, Economics." (2008).

[4] Piggott, Hugh. "Windpower workshop." Centre for alternative technology publications (2000).

[5] Khurmi, R. S., and J. K. Gupta. "Machine Design." (1982).

[6] Hansen, Martin OL. Aerodynamics of wind turbines. Routledge, 2012.

[7] Wong, Samuel HengHsin. A Parallel Adaptive-mesh Method for Predicting Flows Through Vertical Axis Wind Turbines. Diss. 2011.

[8] Ghosh, Tushar K., and Mark A. Prelas. Energy Resources and Systems: Volume 2: Renewable Resources. Vol. 2. Springer, 2011.

[9] Hansen, A. C., and C. P. Butterfield. "Aerodynamics of horizontal-axis wind turbines." Annual Review of Fluid Mechanics 25.1 (1993): 115-149.

[10] Dey, Soumitr. Wind turbine blade design system-aerodynamic and structural analysis. 2011.

[11] Ebert, P. R., and D. H. Wood. "Observations of the starting behaviour of a small horizontalaxis wind turbine." Renewable energy 12.3 (1997): 245-257. 